University of Denver

Digital Commons @ DU

$1-1-2014$

\title{
The Rise of the Dark Side: Dark Pool Trading and the Two-Tiered Implication
}

Katerina Ruth Mills

University of Denver

Follow this and additional works at: https://digitalcommons.du.edu/etd

Part of the Economics Commons, and the Law and Economics Commons

\section{Recommended Citation}

Mills, Katerina Ruth, "The Rise of the Dark Side: Dark Pool Trading and the Two-Tiered Implication" (2014). Electronic Theses and Dissertations. 434.

https://digitalcommons.du.edu/etd/434

This Thesis is brought to you for free and open access by the Graduate Studies at Digital Commons @ DU. It has been accepted for inclusion in Electronic Theses and Dissertations by an authorized administrator of Digital Commons@DU. For more information, please contact jennifer.cox@du.edu,dig-commons@du.edu. 
The Rise of the Dark Side;

Dark pool trading and the two-tiered implication

\author{
A Thesis \\ Presented to \\ the Faculty of Social Sciences \\ University of Denver \\ In Partial fulfillment \\ of the Requirements for the Degree \\ Master of Arts \\ by \\ Katerina Ruth Mills, JD \\ June 2014 \\ Advisor: Markus P.A. Schneider, PhD
}


Author: Katerina Ruth Mills, JD

Title: The Rise of the Dark Side;

Dark pool trading and the two-tiered implication

Advisor: Markus P.A. Schneider, $\mathrm{PhD}$

Degree Date: June 2014

\begin{abstract}
The United States equity market is made up of both private and public trading venues, creating a framework dark and light trading liquidity. Private or non-publicly visible liquidity is housed in dark venues while liquidity visible to the public sits in light locations. Light markets follow strict real-time public reporting requirements for trade volume and price; their dark counterparts execute transactions without a real-time reporting requirement. The informational asymmetries that result from this difference in reporting create a "two-tiered" market. The dark sector's participants know both the public and dark, private, trade volumes and price, while the public participating in the light market knows only the publicly reported light sector volume and price information. Dark sector participants, institutional investors, then participate in the market using both private and public information, whereas the public investor only has access to the public information. This project seeks to motivate a real-time reporting requirement for trade volume and price in the dark sector of the market in order to remedy this public versus private asymmetry.

The informational parameters in this thesis are only those relating to the trades taking place and their respective volumes and prices, not other outside of the market or participant specific informational parameters commonly used in the study of informational asymmetries. This project is an attempt to bridge both the legal aspects and
\end{abstract}


economic foundations relating to the issues surrounding dark sector reporting. Sections I through IV seek to detail the sector and its regulation while sections V through VII briefly describe the related economic literature and the simple model at the heart of this thesis. Additional relevant citations on many issues outside the narrow breadth of this project can be found in the appendices and bibliography. 


\section{Acknowledgments}

Special and unending thanks to Professors Markus P.A. Schneider, J. Robert Brown, and Tracy Mott whose patience, guidance, and expertise has been and continues to be invaluable in constructing this project and through the past three years of my graduate and legal study.

Additional thanks go to those who are responsible for maintaining the Securities and Exchange Commission and Financial Investment Regulatory Authority regulatory databases. Without your work, navigating the complex system of regulation over Alternative Trading Systems would be all but impossible.

Thanks, no matter how special or unending, could never be enough to thank my mother and father for their constant support and guidance. From the day I first learned the meaning of gratitude and every day after, I will never have the words enough to thank you. 


\section{Table of Contents}

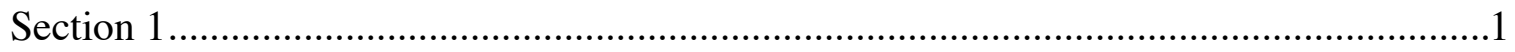

Introductions and Dark Beginnings ................................................................

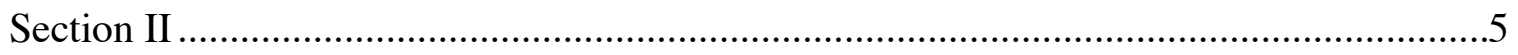

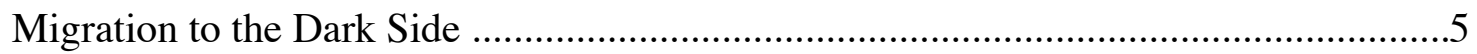

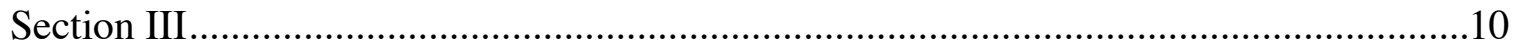

Dark structure, Dark Actors, Dark Forces ................................................................10

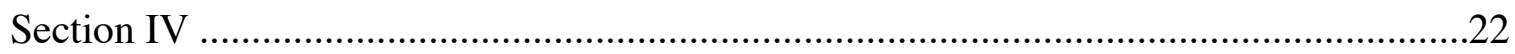

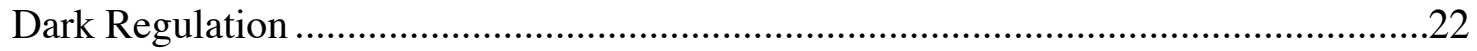

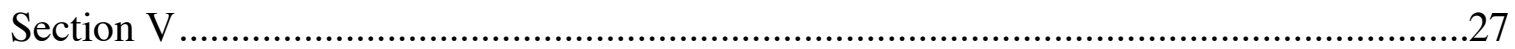

Informational Asymmetries, Dark Impact, Dark Price ............................................27

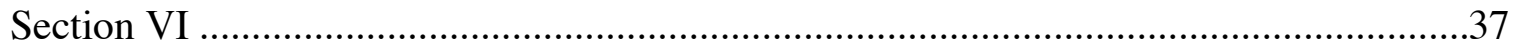

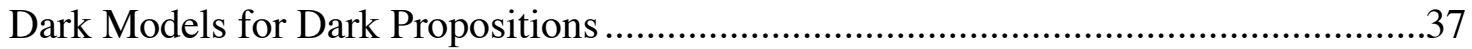

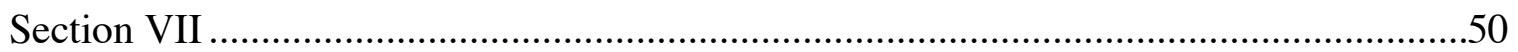

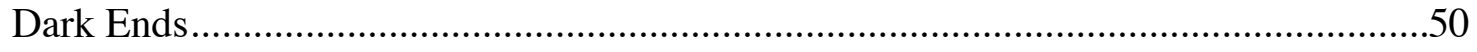

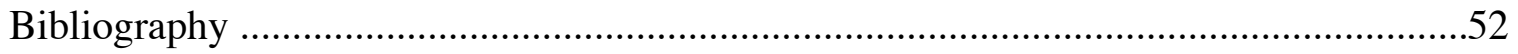

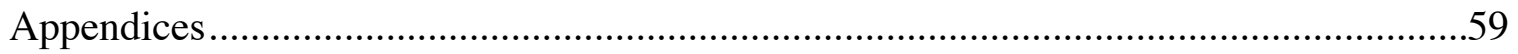

Appendix 1 Regulations and Regulatory Entities ...................................................59

Appendix 2 Terminology ...................................................................................61 


\section{Section I.}

Introductions and Dark Beginnings ${ }^{l}$

Financial markets are vast, every growing, and ever changing. Each day transactions, assessments, expectations, and the process by which markets introduce buyer and seller evolve. The venues where transactions take place are as varied and multifaceted as the financial mechanisms being traded. The United States is a global leader in the equity market internationally and has always stayed several years ahead of its European counterparts and even decades ahead of the Asian markets. With this comes a well-developed and detailed framework of regulations and an even more intricate and developed system of financial institutions and mechanisms. Part of the US dominance in the equity field stem from the surrounding landscape of technologically companies and private equity/venture capital firms surrounding the development of the domestic equity markets. Innovation and development in the land of equity markets are in a constant state of redevelopment, recalibration, and refinement. The battle for market share has been termed a "technological arms race" by many in the industry ${ }^{2}$, as technology seems to lead the market in offerings, assets and mechanisms, and hosting services. The dark sector's

\footnotetext{
1 "The Dark Side of the Force is the pathway to many abilities some consider to be... Unnatural." - Senator Palpatine, Star Wars: Episode III, Revenge of the Sith (2005).

${ }^{2}$ Karl Marx also uses this description in reference to industrial capitalism; many academics outside of the financial sector discourse on the importance of technological competition.
} 
existence is a cumulative result of the market regulatory changes and development taking place from the late 1990's through early 2000's. Technological innovations, regulatory changes, the decimalization of the equity sector, and the growth of capital accumulation and mobility through institutional investors provided a driver for dark venues and their services. Communication, processing speeds, and storage capabilities fundamentally changed the execution of trades and exponentially increased the speed of the market and its related information. Regulatory developments of the late 1990's provided registration requirements for Alternative Trading Systems, required best quote dynamics to induce competition amongst differing trading orders, and regulation FD mandated information disclosure vastly shrinking the opportunity for information arbitrage. Decimalization reduced spreads down from unit "ticks" into decimal values, lowering profit margins and reducing liquidity values at a given price level. Institutional investors with large stores of accumulated capital, sophisticated market awareness, and complex sell and buy side liquidity preferences permanently altered the dynamics associated with trading volume and trade size. Dark liquidity has existed since the inception of the financial sector. Information-dark liquidity in the form of off-exchange trading and within book exchange mechanisms was always a facet of the market. Recent temporal, technological, and regulatory catalysts pushed the dark sector into the large market share it holds today. The old "high-touch" financial market model where the major exchanges held a monopoly over the entire equity sector is fading as the "low-touch" dark equity model takes over an ever-growing market share with an ever growing array of different venues and trading mechanisms catering to the differing needs of the institutional trading giants. 
The dark sector is not necessarily a negative facet to the market as a whole as many have hypothesized. The focus need not be on the existence of the dark sector itself, but instead on the ability of the entire market to find an accurate market price. There are important informational characteristics for determining that accurate price inside the liquidity pools in the dark sector. The volume and price for each transaction in the dark sector are central informational components necessary for the market at large to determine an accurate price. This volume and price information must reach the light market's participants real time in order for the market as a whole to determine an accurate price and for all participants to have the opportunity to trade at that price. Different informational reporting requirements for the light and dark sectors creates separate informational tiers in the market; the public sector is at a disadvantage compared to those who are participating in the dark sector. This dynamic creates concerns for both welfare and fairness for those who lack the capabilities to transact in the dark sector and are therefore trapped in the public market. The informational disadvantage to the public sector prevents its public only participants from meaningfully participating in the financial market because they lack the informational access necessary to transact at the most accurate price. Light sector participants lack the transaction related volume and price information necessary to be aware of the most accurate market price, while the dark sector's participants have access to that information. While a real time reporting requirement for volume and price would not cure the current issues associated with high frequency trading and others associated with our current regulatory reporting system, its 
implementation would rectify the informational inequality among market participants who transact in the light sector with those who transact in both the light and the dark. 


\section{Section II.}

Migration to the Dark Side ${ }^{3}$

Dark liquidity has always existed. In fact it is safe to say that before strict reporting requirements and the development of major exchanges and regulatory oversight bodies to whom reporting was done, all trades were in some sense, dark. The light sector is thought of as the traditional trading scheme because it has been the most publicly visible and prominent trading arena since before the 1930's. The dark side on the other hand has always been shielded from public view and public awareness where possible. From its inception, off book, off exchange, or under the table trading practices have always been dark in the sense that the transaction's participants expressly used the dark liquidity or mechanism to avoid going through public venues. The most important issues for the purpose of this discussion are the benefits and purposes of using the dark sector and how information present in the dark sector is regulated compared to those same characteristics in the light, or reporting, sector.

It is relevant here to comment that the dark and light sectors make up the market as a whole, and that dark and light liquidity can execute one another. In this regard it is an over simplification to discuss the light and dark sectors as if they are two separate markets. The light and the dark sectors make up the trading market as we know it, and

\footnotetext{
3 "Ahh, hard to see, the Dark Side is." - Yoda, Star Wars Episode I: The Phantom Menace (1999).
} 
their relative market share and its implication is, at least in part, the focus of this paper. What follows is a brief overview of what has motivated participants in the past and currently to use the dark sector, and how the sector's transformation has led to the perception of dark liquidity we have today.

The development of dark trading mechanisms and the dark liquidity sector would fail to exist if it were the case that there was no difference between trading in the light sector and the dark. The dark sector theoretically provides market participants with four central benefits their light counterpart does not; confidentiality in the trades executed, reduced or avoided market impact relating to the trades, cost savings through dark venues or methods, and the opportunity for price improvement or profit. These four central tenants make up the rationale behind the existence of the dark sector and motivate the bounds sought by the regulation that have grown to surround the sector itself. Early on these opportunities for informational, price, and anonymity control led some market participants to work trades "off the books" and for other participants to use the early broker dealer regulations (or lack thereof) to execute trades without being forced to enter informational reports about the transactions. While today's dark sector is a much more varied and complicated field, the benefits to making trades in the dark have changed little since the inception of the market itself.

The central benefit that has remained perhaps the strongest motivation for partaking in the dark sector's transactional offerings is the ability to reduce market impact (or preserve price improvement or price control abilities). A reduction in market impact rests on several dark-ness related assumptions. The first of which is that the trade 
itself actually carries the potential to impact the market; small trades leave little market impact whereas large or block trades can have a serious impact on the trading price of an asset where trading activity is visible. On an exchange where information is constantly displayed regarding trading behavior the supply of and demand for a certain asset determines its price. If a large block of shares placed into the exchange for purchase the supply would greatly increase and without an equivalent increase in the demand for that asset the price would decline. This price drop is the negative market impact institutional or large block investors are trying to avoid by executing their block trades through dark frameworks. Institutional investor interests in keeping large or block trading as "quiet" as possible also rest on preventing the negative implications that result when others are able to "see" the trade crossing the market. (SEC Proposed Rule on Dark Pools, 2013)

Other benefits relating to the anonymity of the transaction and the opportunity for relatively low costs ${ }^{4}$ in transacting away from the major or light venues are the point of much current discussion. Developments in reporting requirements made even dark sector transactions information laden. Where transactions would be reported at delayed times relative to the public sector and while those reports may protect some information regarding who transacted the trade itself, the communicative and informational capabilities of the current millennia had made anonymity a benefit of the past. A similar issue has arisen with the cost of transacting trades it the dark sector. While the cost to each individual transaction may be equal to or relatively less than those transactions in

\footnotetext{
${ }^{4}$ Costs both in relationship to the transacting with the dark venue and reduced costs for transacting large or controlled trades that may be costly when transacting with an exchange.
} 
the light sector; the cost of remaining informed about dark transactions may be preventatively high. The informational analysis and synthesis capabilities required to remain informed with regard to other transactions taking place in the dark sector may require the participation in multiple different dark pools and the ability to synthesis trade information flowing from each individual dark venue or aggregator. Without these capabilities, the market participant is in essence just as blind as the public with regard to other dark sector transactions. Transactional costs in this sense include not only the costs associated with completing the transaction, but also the risk that other dark players know information that you do not. While trade anonymity and low transactional costs were previously central benefits to trading in the dark sector, they are no longer clear points differentiating life in the light and life in the dark. Instead, price controls and market impact controls emerged as the dominant features driving dark participants to transact.

This focus on price and market impact has also led to a change in the type of mechanism dark transactions go through. In the past off book, off exchange, and other behind closed door transactions could take place in a multitude of different ways; upstairs markets, broker dealer trades, and on actual dark liquidity venues. This dark sector has evolved from a series of varied mechanisms into a landscape of primarily "crossing" oriented venues. The focus on impact control and price benefit has led to a dark sector landscape dotted with transaction focused venues and venue aggregators. These venues provide participants with access to a variety of different informational control options and access to other dark participants and venues. These informational controls are now almost entirely related to the size of the trade being reported, the division amongst shares in a 
particular trade, and the temporal and price related controls regarding the actual execution of the trade itself. While the dark landscape holds a plethora of venues, the venues all offer similar trade types, services, and conform to one of several venue designs. The dark sector is no longer as a varied as it once was, at least in part due to the narrowing of benefits flowing from dark transactions. The growth in market share of the dark sector is also likely a result of the changing dynamics of market participation. Many see the increase in size and number of institutional investors while the individual market participant has become more and more rare. A growth in the presence of institutional traders means a growth in the number of market participants capable of transacting in the dark sector, while there are no empirical studies to support this market change, the increasing presence and power of institutional investors in the market suggests an increase in the use of alternative trading mechanisms. 


\section{Section III.}

\section{Dark Structure, Dark Actors, Dark Forces ${ }^{5}$}

The dark sector is made up of many venues and many aggregators. Colloquially these are often called "pools" and these pools refer to the groups of liquidity within the sector itself being housed in different venues or aggregators of venues. The dark pool does not represent a single venue or even a single type of equity trading mechanism. A Dark Pool can be defined broadly as any mechanism or venue that houses dark liquidity. ${ }^{6}$ Dark liquidity is anonymous or non-displayed liquidity, or trade ready shares of a certain asset which have some level of information concealment/control related to their trades. Liquidity is anonymous or non-displayed if it is submitted or transacted through a venue confidentially and without full visibility to the market at large. The dark sector is then the culmination of all the dark venues and trading mechanisms through which liquidity can be transacted in the dark (without reporting). The assets traded in the dark sector are the same stocks and assets that are traded on the light market (generally, NSM stocks).

While the light market includes both the primary or initial offering (IPO) market and the secondary market for the NMS stocks it carries, the dark market is only comprised of secondary trading liquidity; trades where shares are offered for the first

\footnotetext{
5 "Size matters not. Look at me. Judge me by my size, do you?" - Yoda, Star Wars Episode V: The Empire Strikes Back (1980).

${ }^{6}$ Definitions for key terms can be found in Appendix II.
} 
time to the public do not take pace in the dark sector. Initial offers and primary market sales cannot take place through dark venues. Unlike the light market, the dark sector, for various reasons, tended in the past toward large block trading with a heavy reliance on informational and trade parameters. Block trading transacts shares in large share blocks, groups or pools of 1,000 shares or more. These are the types of trades that would have the most intense market impact if they were transacted in the light and were typically transacted in the dark to avoid those implications. However, the types of transactions currently taking place in the dark sector are smaller groupings of shares, 300 shares per transaction on average. What used to be large single block transactions are now split into smaller groupings of shares to be transacted through several venues simultaneously. This both helps to avoid shallow liquidity issues venue to venue and controls the leakage of trade information coming out of any single venue relating to the size of the full transaction. The dark sector depends greatly on transactional liquidity controls and strong informational control of leakage with which to manipulate and hide these massive multipiece transactions.

These two control facets come in many different types of pre-packaged trade offers and many different varieties of trade venues. These venues carry a vast array of services and functions and each venue is its own unique entity seeking to provide deep liquidity with a strong control on certain informational parameters related to the exchange (minimizing information leakage). The quintessential dark venue is the Crossing Network $(\mathrm{CN})$. The crossing network is the most simple and most common venues found in the dark; other varieties of dark venues are typically structured based on the $\mathrm{CN}$ model. The 
CN allows participants to enter priced orders and transact the order when matching interest is available. The single price for the transaction is derived from the light market price. (Securities and Exchange Commission, "Regulation of Exchanges," 1997). Crossing networks, working entirely in the dark, allow participants to control a great deal of the information relating to their executions and their simplicity helps to avoid information leakage and over-complication of transactions.

All dark mechanisms do not share the same level of informational controls with marked differences between CNs relating to how much informational freedom or control is available during a trade. In this context, not all dark pools are equally dark. Some pools allow for different forms of information to leave the pool, "leak out," or simply be available to other participants in the pool, for this reason some venues are termed Gray Pools instead of carrying the normal dark nomenclature. The central commonality to all dark equity mechanisms is some form or degree of information control with regard to the trade itself.

Fundamentally, trades are executed in the dark in a similar fashion to those in the light. Order parameters and execution requests function in almost the exact same fashion for the most part. In some instances IOI's (Indication of Interest) or mechanism specific communication capabilities allow dark participants to employ more evasive or more communicative strategies for moving their assets than those capabilities afforded by the light market. However, the most important difference is the dark sector allows for explicit display or information parameters to be controlled with regard to the order. When trading across a dark venue (depending on the venue's acceptable parameters), the investor can 
control the amount of information that gets displayed relating to his order. The order's informational components can be manipulated so that its volume is completely hidden, partially hidden, or fractured into multiple pieces described above. It is useful to note that the assets transacting through a dark venue, a gray venue, and those transacting in the light are not separate. Though informational parameters differ greatly amongst the trades that have taken place, dark, gray, and light orders can execute together or on one another. This means that some of the informational requests of parameters can include making part of the order dark and part of the order light, or any combination in between.

The dark sector is predicated on the ability to execute transactions in order to control the display or leakage of information relating to the trade itself. Part of this control requires that a venue be able to transact the entire or the planned portion of the transaction without having to seek additional liquidity from another venue. The more a trade has to be broken up for execution on different venues or gets "shopped" around from venue to venue in an attempt to find liquidity to transact the execution the more information leaks out into the market and the less dark the transaction becomes. As time and number of venues increase, the risk of information leakage among the venues grows, and the trade becomes less and less dark. The necessity for access to deep liquidity in each of the venues themselves is part and parcel to the venue being able to completely control the information it releases to only those participating in it and not the participants at other venues. If the venue or aggregator has to go outside its network or to other independent venues to find additional liquidity information leaks out as a result of venue contacting additional venues about the transaction. 
Dark mechanisms report trading parameters and opportunities to trade to their participants. They do not report the information regarding their transactions and the information present in the pool itself (interests to transact, pings, and other venue related communications) to the public at large, only the pools participants are privy to those informational pieces. ${ }^{7}$ Only participants in the pools gain information about the trades taking place, the volume of liquidity available in the pool, the information on future trades, and other opportunities within the pool or venue itself. Though transactions that take place in the dark may be invisible to the light market for a period of time, it is not the case that the venues themselves do not carry information. The venue must connect buyer and seller for any transaction to proceed, and for that to take place, pool participants must constantly be informed about trade opportunities, possibilities, the liquidity available, etc. The difference in who gets the information in the light (the general public) and who gets it in the dark (only pool participants), has led to the dark sector being classified as a private market while the light is the public market. ${ }^{8}$ In the public light part of the market, all trading information is disseminated to the public at large through real time trading information posted on open and accessible mechanisms (SEC Open Meeting Fact Sheet, Oct. 2009), while in the dark, the venues report small informational tags or informational subsets real time to their participants. This

\footnotetext{
${ }^{7}$ Dark venues report trade volumes to CTA in delayed or non-real time reporting. CTA then distributes that information in the same method as real time (light) exchange reporting. This reporting does not include the information relating to pings, IOI's, or other venue specific pre-trade information.

${ }^{8}$ This dynamic may also represent a strategic attempt to allow market distortion and price setting within the pool framework; these issues are outside the breadth of this thesis.
} 
informational reporting dynamic has led many to call the current market a two-tiered system; where those predicating in the dark sector have both the information disseminated through the dark pools in which they participate and the information available to the public at large, while the general public only has the information that results from real time reporting in the light venues (SEC Release 2011).

The result of this dynamic is the dark sector's participants have more information than is afforded to the public through real time reporting, making the dark participants the top tier with more information and the public becomes the lower tier with only the information reported by CTA. This inequality in informational access is only exacerbated by the method in which dark participants can participate in the market as a whole. The market's dark sector participants are institutional investors; large, heavy in assets and capital; typically investment firms, major banks, and other major market movers. ${ }^{9}$ These major players are sophisticated in their market experience, expertise, and their technological capabilities. They operate in the light and dark sectors concurrently using strategies and methods of mechanized and by hand trading regimes.

"In practice the largest payers are likely to employ multiple strategies. They may tap the light and dark markets, simultaneously advertise and hide, use multiple dark venues, publish indications of interest rather than firm orders, use deceptive strategies to shake off any form of front runners, and use multiple brokers in some situations and take direct control of their orders in other cases.” (Banks 2010)

Institutional investors carry massive stores of mobile capital and have developed resources for measuring the market and its dynamics; institutional investors are the

\footnotetext{
${ }^{9}$ Institutional investors are the Dark Actors in this model. They are (pardon the analogy) the sith lords of the modern financial market; sophisticated and holding sufficient capital to control the dark-light relationship completely.
} 
quintessential purveyors of dark and high-volume trading. Dark venues and the nodisplayed sector play host to high level gaming, algorithmic trading, and other dark roaming tools that make dark market participation increasingly dangerous for the average or non-institutional investor. Beneficial executions through the light and dark markets require an extremely developed tactical approach common almost exclusively to institutional firms that house dedicated and intricate algorithmic trading capabilities, stores of deep liquidity, and the ability to seek expertise from brokers and block-dealers. The institutional investor's goal in participating in the market is to facilitate reaching a better price by strategically participating in the dark and light sectors of the market.

Institutional investors are big, they are backed by hundreds of millions of dollars in capital and assets, and they carry the most well developed and experienced market strategies that exist. However, one of their most important features is how they tend to participate in the dark sector. Because dark reporting is only made to pool participants, only the participants in each individual pool know about the availability of transactions or liquidity. In order to be party to all available transactions and all available dark information, institutional investors have availed themselves of participating in many, if not all, the venues and aggregators in the dark sector. Consequently, the institution knows the information present in every venue, and therefore, all the information present in the dark sector at any time. Being privy to every pool is costly and only the biggest institutions can foot the bill and the costs associated with dealing with the bulk of information they receive. This participation dynamic produces an extreme to the twotiered informational groups where the big institutions have access to all the information 
present in the market at any time, all the dark information and any public information available, while the public only has access to the information stemming from the light sector.

This presents major fairness and welfare concerns for the public's ability to meaningfully participate in the market. Excluding long-term investment, making money on the market relies entirely on knowledge of the accurate or appropriate price for a stock at any given time. Without access to the full gambit of available information relating to the appropriate price being offered and asked for a given stock in any sector of the market the public cannot properly price its own transactions, and more importantly the light sector may carry an inaccurate price. These informational parameters will be discussed later in relation to market efficiency models; however, the focus here is not on market efficiency, but instead on the welfare concerns that result from an unequal distribution of informational access among market participants. The institutional investors are privy to information about the volume and price for the transactions taking place in the dark sector real time and the public is not; dark participants are aware of all facets relating to an appropriate price and the public is not.

In the light sector exchange trades are reported or displayed as they take place, real time. So the public is made aware of the changing supply and demand dynamics of each asset as it gets traded in and out of the exchange. The public has information about the depth of liquidity, breadth of the market, and the markets determined price for any asset being traded. In the dark context it is quite possible that none of this information exists. In the dark market sector, there may only be certain informational parameters 
available with regard to a trade, the volume in a pool, or the volume in the sector as a whole.

Trading volume flowing across dark pools is measured in a myriad of ways and few venues use the same metrics for examining their own trading volume. The four more common measurement parameters for the equity sector are; the immediacy at which trading can take place, the breadth of a given market, the depth of that market, and the resiliency of the security (asset) itself. Immediacy, breadth, and depth all reflect the liquidity a given venue has in a certain asset; how fast the trade can be executed, how much can be executed at once; and spread at which a price can be determined. Resiliency of the asset reflects the nature of the price stability associated with the asset and how easily it might fluctuate. One central issue with regard to the information pertaining to each one of these parameters is that by the very nature of being dark, the venues housing dark liquidity are the only entities that have access to this information about their markets and it is to their benefit to be the most liquid and appealing they can possibly make themselves.

"Measuring liquidity in a marketplace is a complicated proposition, made even more complex by growing pockets of activity in non-displayed forums, where record keeping and data reporting are not always mandatory or uniform, and where certain venues may have some interest in presenting statistics in one direction or another." (Banks 2010)

The current reporting systems, fail to distinguish between light and dark trading activity and they do not require a standardized method for volume calculation. For example, there are several different metrics for "counting" the number or volume or orders that come across an exchange interface; metrics relate to the number of orders 
processed, those actually executed, and several different measures exist for how to count those orders (some venues double count, some single count, some only count executions, and others include all orders that 'touch' their venue). In this case it is possible for the same number of orders to be counted at least four different ways, leading venues to constantly calculate their trading volumes differently.

The basic result is not only does the general public have little idea as to what goes on in the dark, even where the dark sector reports its volume and general trading information to the regulatory bodies, the metrics for volume, trades, and market share present a varied and unreliable measure. In short the only parties who know how much trading activity and how much volume is being transacted through the dark sector are the institutional investors participating in the pools and the venues themselves, and even those entities have to manage the differences from venue to venue in volume and trade classification and definition. The dark sector's measurement is almost impossible to take $^{10}$ without specific guidelines for volume, trade, execution, and liquidity definitions and regulations.

Central to the issue of measuring the dark sector, its pools, and venues is the structure of the dark sector itself. In its early years, the dark sector blossomed into a framework of venues each holding small pools of liquidity, and the entire sector carrying a small share of the market as a whole. As the popularity of transacting in the dark progressed, the sector fragmented into many small venues offering smaller and smaller

\footnotetext{
${ }^{10}$ The current estimations as to the market share actually held in the dark sector range from $25-45 \%$ of the NMS market in the United States, and little work has lately been completed regarding the accuracy of either end of these estimations.
} 
pools of liquidity. Fragmentation has both benefits and consequences. While a fragmented nature provides the opportunity for competition, it also has the potential to render trading sub-optimal. Whether or not fragmentation actually leads, through a loss in liquidity, to sub-optimality inside a given venue (as opposed to across an entire market) has been the topic of hot debate and many believe that any loss of optimality has more to do with the structure of the trading mechanism than the fragmentation or loss of liquidity itself. However, there are those who see greater fragmentation across multiple venues as a "potential for system failures to spread quickly and affect the entire market," (Stiglitz; WSLawyer.com, Sec. 19) More from the lack of liquidity than the threat of possible systematic failures, the dark sector has for several years been in the process of consolidating itself. Competition and a general need for access to liquidity to execute block trades gave way to mass consolidation of venues under venue aggregators. While any venue could control some of the parameters with regard to its trade, where there was a lack of liquidity, shopping around venue to venue for liquidity reduced the informational controls associated with the trade itself. The mode from which trades can be given parameters and traded in bulk, pieces, as ice-bergs ${ }^{11}$ or anything else depends on the trade actually taking place in real time across the exchange mechanism; with many small dark venues coming online competition increased and dark sector fragmentation became a growing issue. Liquidity and the fungibility of liquidity and execution are central to the success of any trading mechanism, without access to sufficient commodity volume a trading pool "dries up." While offering specialized and commoditized trading

\footnotetext{
${ }^{11}$ Tip or small subset of the trade is made visible to the light market, while the bulk of the trade is kept dark or hidden (all Titanic references aside).
} 
parameters and structures is the norm in the dark sector, the diversity of venues has spread liquidity thinly and has motivated consolidation among venues and mechanisms in hopes of gaining an increase in depth and liquidity. With an increase in liquidity, trading volumes increased leading to a drop in execution related costs and suggesting that the dark sector experiences highly effective internal economies of scale. The relationship of this consolidation dynamic to the volume or execution volume related regulatory practices will be discussed in a later section, but it is safe to say that the sector itself no longer carries individual or unconnected venues. The vast majority of venues are housed under aggregators or connected through contractual agreements to other venues where informational controls can flow through the aggregator's venues and the connected venues with minimal informational leakage. The consolidation and aggregator developments have side-stepped many of the earlier issues with shallow pool liquidity and inability to complete full transactions present in the more antiquated version of the dark sector. 


\section{Section IV.}

Dark Regulation $^{12}$

The regulation of the securities markets has, from its inception, been based on the notion that providing information to market participants provides fairness (Hatch 2010) and efficient market function (Malkiel 1992). The basic regulatory framework is a system of informational disclosure requirements whereby the nation's publicly held companies submit information through public reporting requirements so the public is constantly informed of the relevant information necessary to determine a proper price and to facilitate informed and fair trading. The earliest securities or national market regulatory acts were the Securities Act of 1933 and the Securities Exchange Act of $1934 .{ }^{13}$ These Acts serve as the foundation to the nation's current regulatory framework and delegate regulatory authority to the Securities and Exchanges Commission. Explicit further refinements of the regulatory landscape did not take place until the 1990's, when restrictions and reporting requirements on brokers, broker-dealers, public companies, and exchanges dramatically increased the amount of information entering the market. ${ }^{14}$ The best price available and the spread of each stock being traded was now made publicly

\footnotetext{
12 "This is some rescue! You came in here, but didn't you have a plan for getting out?" Princess Leia, Star Wars Episode IV: A New Hope (1977).

${ }^{13}$ Citations, explanations, and additional information on regulation, regulatory entities, and governmental bodies can be found in Appendix I.

${ }^{14}$ Regulation OHR and Regulation FD
} 
available, and public companies had to increase their public reporting to include many previously unattainable informational parameters; stock sales, managerial decisions, and other pertinent information. The public was now granted a direct look into public trading exchanges and the companies being traded.

In the late 90 's and early 2000's regulations on alternative trading systems and the national market system changed the previous interpretations and reporting requirements for the alternative or non-major exchanges. ${ }^{15}$ While the systematic requirements for the major exchanges and public companies changed little as a result of regulations ATS and NMS, the alternative or non-major exchanges classified under Sections 5 and 6 of the Exchange Act were formally defined and explicitly excluded from the reporting requirements of the major exchanges. Alternative trading systems include the mechanisms used to trade dark liquidity. Regulation ATS and NMS both excluded the dark sector from following the informational reporting required on the major exchanges and instead instituted a by volume reporting system, which allows for delayed trade volume reports instead of real time trade by trade reporting. Regulation NMS created the volume decimalization reporting system to be followed at all exchanges carrying National Market Stocks. The mass decimalization of the market led to a dramatic increase in the use of dark block trading practices because it drastically changed the market's spread dynamics and best price offering requirements substancially increased the impact large trades had on the market price of a decimalized stock.

\footnotetext{
${ }^{15}$ Regulation ATS and Regulation NMS
} 
Under this framework, the mechanisms of the dark sector register as brokerdealers, and fall within the Alternative Trading System definition under the Acts and have their own particular reporting requirements. The only two hurdles that must be cleared in order to trade as an alternative system and avoid being classified as a major exchange, are first to register as a broker-dealer, explicitly placing oneself under the ATS definition, and second that the trading volume one executes does not exceed $5 \%$ of the national trading volume in that particular stock (NMS stocks). ${ }^{16}$ This orientation on exchange determination in concert with the aggregator venue structure of the dark sector will be discussed at length later. It is useful to note that under the ATS definition the percentage of NMS stock transacted is only a requirement on venues, which actually execute trades. This regulation does not apply to aggregators or brokers or dealers, who do not actually execute trades themselves. The entities connecting traders to venues or to other traders can handle far more than $5 \%$ of an NMS stock in referrals or connects, while it is the venues they connect traders to that are held to the 5\% ceiling. An aggregator can handle $6 \%$ or more in a given stock as long as each of the venues it houses or direct clients to transacts a volume less than $5 \%$.

This framework of regulatory mechanisms worked to motivate an even greater movement into the dark sector. The 1933 and 34 Acts required that the public market always be informed; regulations through the 1990's required a greater and greater informational swath be provided to the public; regulation ATS explicitly removed dark trading mechanisms from the reporting requirements of the major exchanges; and

\footnotetext{
${ }^{16}$ Regulation ATS
} 
regulation NMS decimalized the market as a whole causing price impact to become unavoidable. The public market became so informed and the spreads on decimalized stocks had become so small with block trading causing massive market reaction each time a block entered the well informed market, the dark sector became the outlet. The dark sector allowed for informational controls, reduction in the impact block trading might have on the market, and most centrally, the dark sector was not required to report its trades in real time. It is then little surprise that the dark sector's growth has been nothing but astronomical in the past years and pressures to 'fix' the regulatory gap in informational reporting spurred a plethora of regulatory attempts. (Gallo 2009)

In the fall of 2009 the Securities and Exchange Commission held an open meeting in hopes of proposing a new set of regulation over the dark sector as fears about its strength, market share, and volume began to come to fruition. The meeting was titled, "Strengthening the Regulation of Dark Pools," (SEC Open Meeting Oct. 2009) and specified two central regulatory goals or focus points for the proposed regulation: to require some form of publicly available material as to the investor's interest in the sale or purchase of an asset and to the identity of the venue processing the transaction itself. The proposal was intended to enhance transparency and to promote fairer, more efficient markets for stocks listed in the US. The Commission later proposed a three-part rulemaking (SEC Release No. 34-60997) in hopes of attaining these regulatory goals: [1] to include the information contained within the dark venues in public reporting, [2] to alter the volume requirement under regulation $\mathrm{ATS}^{17}$ in an attempt to force dark venues to

\footnotetext{
${ }^{17}$ Changing the volume marker from $5 \%$ to $.25 \%$.
} 
register as public exchanges, and [3] to change the information disseminated as a result of the delayed volume reporting coming out of dark venues. This regulation was never enacted, but was followed by a 2011 FINRA filing with the Commission in which the Regulatory Authority sought to allow certain alternative venues to be excluded from reporting requirements and other requirements (similar to the aims of regulation ATS), though this attempt was also never made operable. (FINRA Proposed Rule Change, 2011)

As of yet, no new rules have been put into place to balance the flow of information in the public exchanges with information in the dark sector. The implications of what might have been for the 2009 SEC rule proposition will be discussed at length in concert with the model proposed in this project. The orientation of previous regulation has both created the demand for dark sector liquidity and helped to foster its growth. The latest rule-making attempts have not been focused on the right issue of regulation, the informational parameters being reported and the type of reporting taking place. The focus and breadth of previous regulation instrumentally created the demand for the dark sector while also being inadequately and improperly focused to bring about an information balance between the light and the dark sectors. 


\section{Section V. Informational Asymmetries, Dark Impact, Dark Price ${ }^{18}$}

The importance of information has been a pillar of market function and exchange for centuries; exchanges and games of chance were thought to depart from equality or fairness when different participants had different levels of information about the situation or the exchange (Cardano 1564). The efficiency of markets based on the information reflected in its exchanges dates back to the $17^{\text {th }}$ century (Gibson 1889). The notion that complete information makes markets efficient has been the bedrock for informational reporting requirements and the notion of market participant equality almost since the inception of the market itself. The notion of market efficiency was codified in Fama's 1970 Efficient Market Hypothesis (Fama 1970).

A market is efficient if the price being offered on the market for an asset fully reflects all the relevant information available (Fama 1970). This can also be defined as the market carrying a price that is unaffected by revealing information to market participants, in other words, the price already reflects all relevant information (Malkiel 1992). The Efficient Market Hypothesis (EMH) itself asserts that markets are in fact efficient. This claim has been refuted by many, supported by some, and completely

\footnotetext{
18 "If there's a bright center to the universe, you're on the planet that it's farthest from." Luke Skywalker, Star Wars Episode IV: A New Hope (1977).
} 
disassembled by others; and there remains little consensus as to the effectiveness or accuracy of the model itself. However, for the purpose of this examination, the important features of the EMH model are its definitional components and the importance it places on the types, freedom, and completeness of the informational parameters that should go into determining the market price for an asset.

Definitionally, the components and interpretations associated with the EMH can be viewed as moving goalposts as opposed to firm definitions; however, they are of no less importance (Sewell 2011). An efficient securities market can be described as one where, given all available information, actual prices on the market are reliable or good estimates for the intrinsic values of each of the stocks or securities being transacted (Fama 1965 (The Behavior of Stock-market Prices)). The market is one where participants work to profit maximize and relevant information is freely (or almost freely) available to all participants (Fama 1965 (Random Walks in Stock Market Prices); Coase 1960). The market must both fully and quickly reflect all the information which is relevant and available for each of its securities (Fama 1969/1970). This type of market efficiency and complete information reflection in prices can also be defined as efficiency that makes it impossible to make money by trading on current information since that information must already be fully reflected in the price of an asset (Jensen 1978). These definitions, along with the plethora of other re-workings, expansions, and consolidations, are all focused on the central notion of the market being constantly and fully informed in order to be termed "efficient." The most relevant culmination of this notion comes from Malkiel, 
"A capital market is said to be efficient if it fully and correctly reflects all relevant information in determining security price. Formally, the market is said to be efficient with respect to some information set, $\varnothing$, if security prices would be unaffected by revealing that information to all participants. Moreover, efficiency with respect to an information set, $\varnothing$, implies that it is impossible to make economics profits form trading on the basis of Ø.” (1992)

Based on these definitions, the regulatory framework surrounding the information attached to the trades taking place in dark sector, the public sector is not efficient with regard to the information held in the dark sector. In Fama's design the EMH model contains three forms or strengths regarding the relevance or importance of different information in the market being efficient or inefficient. The three forms include; [1] the Weak Efficiency form, where the relevant information already included in the price extends to only information about past prices, [2] the Semi-Strong Efficiency form, where the relevant information set includes all information available to all the market participants, and [3] the Strong Efficiency form, where all information, including private information, is already taken into account in the market price of an asset (Fama 1970/1991). The first and second forms can be regarded as the typical view of the public market or light sector; the previous price movements of a given stock are known to all market participants, and any other publicly available information has already been traded upon such that additional profits cannot be made by trading on the currently available information. The third form, or Strong Form, suggests that even the information held privately and not available to the public market has already been taken into account in the public market price of an asset. Given the current structure, punishing insider trading, the strong form seems an inappropriate application to the real world securities market. The 
notion of private information being reflected in prices has a greater application than the insider or individual with personal information making personal or individual trades model.

The dark sector, also often termed the private sector of the market contains its own information. In a way it functions like the inside trader in the above example, holding information unavailable to the public about recent or current relevant trading activity. The current structure surrounding trade and informational reporting requirements allows for private sector participants to trade on the information in their sector without informing the public of that relevant information set without punitive repercussions. Then it appears that while the regulatory structure for individual traders gives value to personal or insider information when an individual trades personally in the public market; while the same informational components when transacted from the dark sector into the light sector are viewed as valueless. In other words, the regulatory trading framework views private information unavailable to the public learned in the personal or professional context as both private and valuable, while information unavailable to the public learned in the dark sector as private but invaluable, attaching legal recourse to the former and not the latter. Regulators then seem to refute the Strong Form EMH in the personal or insider-trading context while validating the Strong Form in the dark sector to light sector trades. This dichotomy will be discussed at greater length in the section on regulatory proposition.

Perhaps the most interesting intersection of the EMH model provides in the context of the private versus public market sector discourse relates to the issue of price 
determination. Each iteration, version, reduction, and expansion of the EMH and even those that stand to prove the model impossible, improbable and irrelevant support the notion that information in some form is both relevant and necessary in determining accurate prices. It deserves a bit of reiteration here that the dark sector does not find or determine its own price, but derives or uses the price that is being offered in the light market. So the public price is the price used in both sectors of the entire market, and the price being found in the public market is inherently inefficient with regard to the information available in the private market sector (in the real time).

How the price is found in the light market is extremely important. Price determination is a haughtily contested and often debated topic; many different theories, market models, and orientations coming from an even greater number of fundamental theoretical foundations contend that the commodities, agents, and forums of exchange create and mold the price at which a trade is transacted in an ever changing myriad of ways. In the most basic sense, the interplay of the demand for an asset and the supply of that asset can be used as the determinants of its price. When demand increases while supply remains constant the price increases and when supply increases without an increase in demand price decreases, and so on. In the securities market, demand reflects the profit maximizing behavior of the market's participants perceiving a trading opportunity to make themselves a profit (through the change in a stock's price) or lack thereof. This dynamic is stabilized through a requirement that the market makers or specialists at the public market exchanges always execute the entirety of the orders on their books at any time. For example in the public market a supply of shares cannot sit on 
the exchange un-transacted, and an order for shares cannot go unfilled. In order to 'clear' their exchange the specialist or market makers either lower the transaction price to clear surplus supply or increase the price to meet excess demand and so forth. However, the key issue in this framework for consideration here is how market participants know what direction the market is moving.

When transactions take place across the light market, informational reports on each transacted volume and its price are reported real time (seconds). The public is immediately made aware of the transactions, which have taken place, at what price those transactions crossed the market, and how much of the asset was sold. This means that in the light market when demand or supply shifts and transactions begin to move, the market is aware of it and shifts immediately with all participants immediately clearing the market. This type of informational and pricing model is considered both "fair" and "equitable" in the regulatory context, and the framework of informational reporting for trades that take place in the public sector seeks to keep this "fairness" intact. The reporting of trades and their prices seeks to inform all public market participants of the movements in the market, in essence informing them of the appropriate price that a stock can be transacted at for any given time. This publicly reported and publicly determined price is then used in the dark sector as a price marker for its transactions.

The non-reporting or dark sector, by definition, cannot find its own price. There is no dissemination of information on the supply of, demand for, or volume of any stock in the non-reporting sector. There is no requirement that non-reporting venues execute all orders, demand for, or supply of any given stock. Within a single venue or aggregator, 
informational parameters exchanged between venue participants may give sufficient information as to what the demand or supply of a given stock in that particular venue might be, but without the price provided by the public market that inside venue information is likely insufficient to find an accurate price. ${ }^{19}$ The notion that the market has two-tiers of informational knowledge rests on the knowledge participants have about what price should be available for making their transaction. The dark sector is aware both of its own supply and demand for a given stock, and of the supply and demand for that stock in the public market. An asymmetry or meaningful difference in information is created when those two supply and demand relationships or those two prices do not match. When the price being offered in the light market and the price available in the non-reporting market do not match, the dark sector gains an informational advantage over the public. Institutional investors privy to the knowledge about the price difference can act on it, trading in the light, in the dark, or using both sectors, while the public cannot act on the information it doesn't have and may lose the opportunity for price benefit because of it.

One key note worth repeating, there are many different forms of information and this project only seeks to provide motivation for dark sector volume and trade reporting as a means of informing the public sector of the information on trade volume and price in the non-reporting venues. Other projects and the vast majority of research on informational relationships in different market sectors within the greater securities

\footnotetext{
${ }^{19}$ This dynamic is also present in the light market; where a sufficient amount of liquidity in a stock has moved or been transacted in the dark market, the light sector may then be unable to find an accurate price. Insufficient volume, or liquidity in a stock can make its price unrealistic and inaccurate.
} 
landscape discuss informational asymmetries in a more detailed and nuanced fashion. The previous models discuss informed and uninformed investors relating to levels of individual information that some investors know while others do not. This dichotomy, while indicative of the same relationship as the dark participants and their light counterparts, has a different type of information at its core and a plethora of different nuances and outcomes with regard to what informed participation means in the context of the reporting and non-reporting sectors. In these studies the informed traders typically carry information that comes from outside the market, information with some sort of public time horizon (to be discussed following). The traders come into the trading venue carrying information the public is as of yet unaware, information from outside the dark and light sectors of the market ${ }^{20}$ and trade on that information. This style of informational asymmetry carries a heavy and extensive foundation of research both theoretical and empirical. ${ }^{21}$ The broad foundational behind the study of informational asymmetries in finance stands to support the concept that with informational differences in market participants come disproportionate profit and benefit availabilities. Market participants with more information have a greater ability to profit from that information because they know the appropriate or accurate price for an asset, while the uninformed do not know what the appropriate price should be. In its more simple sense, this type of informational

\footnotetext{
${ }^{20}$ This type of information can be information relating to a forthcoming news report, insider information, or any informational parameters from outside the market the informed trader knows while the public does not. This information can also be described as the information that the market is not yet efficient with regard to, or with which the trader can still make a profit.

${ }^{21}$ Pertinent citations listed in bibliography.
} 
disadvantage is the motivation for insider trading prohibitions and support for disregarding the strongest form of the EMH. However, there is disagreement among scholars as to how non-reported or hidden trading activity fits within the framework of informational asymmetries. For many, the existence of hidden trading activity reduces the ability of the market to find an accurate price, or increases the disparity between those who are informed and those who lack information (Ye 2011 and Kyle 1985).

These models typically represent information as having a horizon, or only being useful for a certain period of time. For example, this information could be the knowledge a certain trader has about an earnings announcement yet to be reported, and the horizon represents the time at which the report will be made to the public. Before the horizon has been reached the trader has the information, while the public does not. This structure functions well as an analogy for the type of information available to dark sector participants because the reporting structure in the dark sector has an important horizon for when the volume related information relating to the trades within the dark pool will actually be made known to the public. Current US regulation creates a small but viable horizon for the trade information within each venue where pool participants are aware of the trade volume, and price, but the market at large has yet to be informed through CTA reporting. However, this is only viable as an analogy since previous informational models do not focus on the information contained within the dark pool itself but focus on trader information brought into the market from outside with a horizon based not on trade reporting, but on public informational releases. 
Zhu (early access December 2013) reflects a detailed culmination of the venue and dark pool specific research on these types of informational asymmetries and produces a persuasive argument for the inclusion of dark venues improving accurate price discovery. This model and various others details the importance of motivating informed traders into participating in the market in order for their trading behavior to add information to the market necessary to determine an appropriate price. Zhu shows that this self-selective behavior of informed traders employing anonymous-venues may actually help the market to find appropriate prices so long as the volume and trade information from dark venues gets reported real-time to the public exchanges. This informational dynamic is the best balance and the most helpful academic work in putting this thesis project into its proper place with regard to other market information and informational asymmetries projects and research. The following regulatory suggestion seeks to motivate a real-time reporting requirement for the trade volume and price information within the trades taking place in the non-reporting sector only because of the price information laden inside the trading itself. While research on informational asymmetries has focused on the information traders and participants bring to the market from the outside, this project seeks to provide an extremely simple motivation for informing the market at large, not of outside information, but of the trade volume and price information inside the venues and trades within the dark sector. These are differences in information access between the two market tiers relating strictly to trade volumes and prices in the dark sector. 


\section{Section VI.}

\section{Dark Models for Dark Propositions ${ }^{22}$}

Because of the difference in reporting requirements currently in place for light and dark transactions, the information received by the public is different than information promulgated through dark channels. This informational case comparison makes the opportunity available for dark market participants to benefit from the public's lack of unreported information by making a multi-part transaction using both the light and dark sides of the market. Because the public does not have the transactional information available to dark participants, the public can miss opportunities for price improvement and allow dark participants to benefit from their missed opportunity. Below is a highly simplified explanation of three different transactions and the three outcomes for transaction participants. Following the brief description is a discussion of the results when the simple case comparison is compared to various reality issues.

In these three cases the prices and risks are associated with the sectors that transactions take place in, not with the asset being transacted itself (as is usually the case when prices are discussed crossing the equity market). This focuses on a single block of shares made up of a single asset. The price differences are related to the venues in which the trade is being made and reflect the laden information being reported at each stage.

\footnotetext{
22 "We meet again, at last. The circle is now complete. When I left you, I was but the learner; now I am the master." Darth Vader, Star Wars Episode IV: A New Hope (1977).
} 
The dark sector participant is the typical institutional investor and the public investor (or purchaser) is a market participant who does not get the information in the dark pool until the delayed dark pool reporting takes place.

This simple comparison involves an institutional investor making a one or two part trade; light market only, dark market into the light market without real-time dark reporting, and a dark to light trade with real-time reporting. The investor seeks to purchase a large volume of a single stock from the market at large and, for all intensive purposes, has no preference as to which market he uses so long as he can purchase the shares as cheaply as possible. The three trades all take place across a single time period consisting of three segments from $T_{1}$ to $T_{3}$. Each of the transactions begins at $T_{1}$ and is completed at $T_{3}$. As each trade crosses the market from start to finish the price moves from $\mathrm{P}_{3}$ to $\mathrm{P}_{1}$; moving from the lowest price $\left(\mathrm{P}_{1}\right)$ through $\mathrm{P}_{2}$ and finishing at the highest price $\left(\mathrm{P}_{3}\right)$. Each price increase is equal to the previous one. It is also assumed that there are no transactional differences in costs between transacting in the light and transacting in the dark. These are strong assumptions but result in a meaningfully simple outcome, which motivates a clean and simple discussion of the reality associated with each of these assumptions.

Case 1: Traditional Public Exchange Transaction

Purchase across the light market and only the light market 


\section{Case 2: Dark to Light Without Real-Time Reporting}

Purchase in the dark market followed by a Purchase in the light market; Reporting of the dark transaction (increase in demand) does not take place until after the light transaction

\section{Case 3: Dark to Light With Real-Time Reporting}

Purchase in the dark market followed by a purchase in the light market under a real-time dark trade-reporting requirement (dark transaction is reported before light transaction takes place)

Each of the three simple models provides a different outcome for each market participant. In Case 1 the institutional investor purchases a large volume of shares (1 million shares) through the light market and only the light market. The second the purchase order enters the light market and transactions ensue, real time reporting of each transaction (each share or smaller group of shares being sold to the institutional investor) informed the public that the demand for the stock has increased, that volume is transacting across the market, and that the price associated with the stock is rising. The shares bleed across the market as supply fills his order, share-by-share, or group-bygroup. The entire 1 million shares are not purchased in a single clump at a single price. The price moves from the lowest $\mathrm{P}_{1}$ to the highest $\mathrm{P}_{3}$ but the institutional investor does not know how much of his desired volume will trade at what price and he cannot control how many units cross the market at various prices. The purchase order for his large volume of shares across the light market may immediately increase the price to $\mathrm{P}_{3}$ forcing 
all of his shares to cross the market at the highest price, forcing him to purchase all of his shares at the highest possible price.

In Case 2 the institutional investor conducts a two-part transaction. He makes his first purchase across a dark venue. He purchases the first half of his 1 Million shares through a dark venue and as a result the transaction and its price are not reported real time to the market at large before he begins his second transaction; purchasing the second 500 thousand shares through the light market. Both the first transaction and the second transaction enter their respective venues at $\mathrm{P}_{1}$. The First transaction across the dark venue transacts in its entirety at $\mathrm{P}_{1}$. The second transaction then enters the light market at $\mathrm{P}_{1}$ because the public-market it still unaware of the first transaction (unaware of the increase in demand for the stock in the market as a whole). In the course of the second transaction the stock crosses the market moving from $\mathrm{P}_{1}$ to $\mathrm{P}_{2}$. The institutional investor was able to buy the entire stock volume with the first half at $\mathrm{P}_{1}$ and the second half at some price between $\mathrm{P}_{1}$ and $\mathrm{P}_{2}$. The market price associated with the stock does not progress to $\mathrm{P}_{3}$ until the delayed reporting from the private sector informs the public sector that the first transaction took place (informs the public market as to the full demand for the stock on the market). Once this report takes place the institutional investor holds all 1 million shares, now all worth $\mathrm{P}_{3}$, but he purchased those shares at a price between $\mathrm{P}_{1}$ and $\mathrm{P}_{2}$. In short the institutional investor holds the same volume and worth as he held at the end of the first transaction, but he purchased the shares at a much lower price. Also, in model 2 the public did not benefit from selling its shares at a price between prices $\mathrm{P}_{2}$ and $\mathrm{P}_{3}$ 
because they were unaware of the first transaction's information on the increased demand for the stock on the market as a whole.

In Case 3 the institutional investor makes his first transaction through a dark venue in the same fashion as he did in Model 2. He transacts the first 500 thousand shares at $\mathrm{P}_{1}$. However, in this scenario the volume and price information related to his first trade are reported to the public market real time. Moments following his first transaction the public market is made aware of the increased demand for the stock he purchased and increases its price from $\mathrm{P}_{1}$ to $\mathrm{P}_{2}$. The institutional investor then proceeds to make his second transaction in the light market, purchasing another 500 thousand shares. This time, the transaction enters the market at $\mathrm{P}_{2}$ and transacts across the market moving from $\mathrm{P}_{2}$ to $\mathrm{P}_{3}$. Again at the end of the transactions the institutional investor holds 1 million shares all valued at $\mathrm{P}_{3}$ and he has paid some price between $\mathrm{P}_{1}$ and $\mathrm{P}_{3}$ to get the shares. In this scenario the institutional investor could still control the price of his very first transaction in the private sector, purchasing the shares at $\mathrm{P}_{1}$, the key difference here is that the public did not miss out ${ }^{23}$ on the chance to sell its shares to the institutional investor between $\mathrm{P}_{2}$ and $\mathrm{P}_{3}$ when he went to make his transaction in the public market. In this case, the institutional investor has the opportunity for arbitrage, more limited than in the second case, but the level of control still available through the dark sector could be considered a form of insurance against the risk of an erratic price jump if the transaction was entirely transacted in the light. This case preserves a benefit to transacting in the dark

\footnotetext{
${ }^{23}$ The public does not recognize the entire price increase, some benefit still remains for transacting in the dark sector for the institutional investor. However, the public does not miss as much of the surplus transfer as they did in the second case.
} 
sector, while still protecting the public from completely missing out on the opportunity for price improvement.

The reporting requirement, in particular the temporal requirement, separates these two public and private trade scenarios. In the current regulatory framework the private market participant can make market moving trades without suffering the price impact of his trade by using a quick (but not necessarily high speed) two part transaction from the private into the public sectors of the market, while still benefiting from the transaction when delayed reporting takes place. A similar, though reversed, transaction can be facilitated to avoid price impact in the sale of stock by an institutional investor. This model is extremely simple, if not over simplified, however, the more realistic the discussion of its price, transaction, and other concerns the more intense the disparity between the private and public participants.

One key point of discussion is this comparison's dependence on a simple price structure. The price movements resulting from the purchases of large volumes of shares across the different venues are obvious and simple, however, the assumption that each of the prices achieved are equivalent is a stretch. It is more than likely that prices achieved at each stage in the model above differ from venue to venue. It is possible that the cases all begin at different prices, reach different prices in the interim and finish at different times. None of these price differences change the fact that the institutional investor has the ability to arbitrage and to control the appropriation of transaction surplus from the public side of the transaction. In simple terms, without real time reporting the institutional investor can control the entire surplus or price improvement and funnel it 
towards himself. With a real time requirement the institutional investor can arbitrage in the dark transaction, but cannot prevent the public from taking price advantages that result in the light market. In this instance it may also be true that the bifurcation of the total trade volume here into two equal halves is a vast over simplification of the institutional investor's ability to control the amount, divisions, and trade volume that is transacted in each sector during the trades. For example, the private participant can balance his trade into many smaller subsections and then transact those pieces in meaningful and intentional ways to both strategically move shares into and out of the private sector while simultaneously moving them into and out of the public sector to create the greatest benefit to the investor. The availability of this volume control dynamic is at least partially responsible for the changes in trade volumes crossing dark venues dropping on average over recent years. The simple single group block trade is no longer the norm, broken or separated blocks are the typical transaction.

This creates both a more strategic break up in share groups being transacted in each market, but also creates important distinctions in the price changes taking place between the entering and leaving prices in each of the markets. The distance between buy and sell prices or the spreads on markets are often sighted as being indicative of market volatility. This type of transactional control coming out of the private sector of the market has often been sighted as a cause of increased spread in prices and increased market volatility (Degryse 2011, Jiang 2011, Weaver 2011, Comerton-Forde 2012, among others discussed the market share held in the private sector of the market as being indicative of volatility levels). Others have found that the market shares associated with a dark or 
private sector behaving in this manner may not lead to increasing volatility (Buti 2011, Ye 2011). The previous studies relating the behavior of private sector participants and the volatility of the market as a whole have generally assumed that the private sector of the market reports its volume and price informational parameters to the public real time. ${ }^{24} \mathrm{It}$ is safe to assume that where dark sector participants can both use advanced strategies to move stocks and prices in their favor and the public market remains unaware, even for a short period of time, these strategies are likely move the market's prices in volatile or unpredictable ways.

In short, the price assumptions relating to the movements of prices as stock volume crosses the market are an oversimplified version of how demand changes might inform the dark without informing the public. The dark sector's participants are more aware and able to strategically trade than could be modeled in this simple comparison. Many have sought to detail the behavior and strategies used by dark sector participants. In short, the distances between prices, movements of the entry and exit prices, and the general volatility of the market's prices during and resulting from transactions only serves to increase the value of the volume and price information contained in the transactions taking place in the dark sector. With the growing market share transacting in the dark market, the gains that result from these strategic trading practices cannot be minimal or unlikely. The sophisticated use of dark and light informational parameters and

\footnotetext{
${ }^{24}$ Real-time private sector reporting exists in the vast majority of markets outside the US, leading many who study the impact of various dark sectors to assume the real-time transfer of information relating to price and volume from those sector to the public.
} 
reporting requirements presents a profitable market outlet for institutional investors to strategically participate in the upper market tier.

The venues at which these transactions take place also come with issues, differences, and complications of their own. The venues in the public and the private sector execute trades in drastically different manners and as a result, have different temporal qualities and costs associated with transacting in them. In the dark sector trades may be executed through many venues in order to find sufficient liquidity or some transactions may not be completed in full because of different constraints on price, time, or venue number. In the public sector, market makers and specialists clear the market balancing prices, demand and supply guaranteeing that transactions take place, but never guaranteeing an execution price. While the NMS stocks are the same and the general buy and sell structure of the two sectors matches, allowing liquidity held in one sector to execute liquidity held in the other, the structure of the exchanges dramatically changes the temporal signatures on how transactions are executed.

Assuming the time periods across which this model transaction is processed over simplifies not only the transactional capabilities and trade offerings in the two sectors, but also restricts the relationship the institutional investor has with the dark venues and that which the public has with its light exchanges. In the dark sector, interest in making an exchange is necessary to seek out other parties with whom to transact, while the public simply enters its shares onto the light market without having to seek out other participants with whom to transact. A dark sector participant is much more personally involved with the venue through which he transacts, indicating his interest to transact, setting volumes 
and prices he seeks with his transaction, and reacting to results when his trade is either accepted or volume is returned to him. The structure of the light market does not facilitate this type of involvement. These types of dynamics can also be termed transactions related costs because of the effort or time necessary to facilitate the transaction itself. In this manner, the dark sector can require more effort in facilitating the transaction than the light sector.

Transactional costs even differ among the means used to make transactions within the light sector and within the dark sector. Some have speculated that the venues in the dark sector can better diffuse of reduce transactional costs, while others have cited the various costs of remaining informed while also participating in the dark sector as so costly that they hinder participation in the sector as a whole (Conrad 2003, Brandes 2010, Domowitz 2009, among many others). In short, differentiating between the costs of transacting in either market carries nuances that are extremely difficult to measure and depend highly on the type of transaction being sought and the participant seeking it. The simple models assume that those choices are not at issue for neither the institutional investor nor the public, and no choice of venue is given to either. This is both rigid and simple, meant only to show that delayed reporting requirements lead to the public missing out on opportunities for price improvement.

The issue of venue choice is not a menial one. Self-selection and selection biases are crucial elements to the current shape and structure of academic research surrounding the existence of dark sectors in any market. The dynamics, motivations, and structures surrounding venue choice are outside the narrow breadth of this regulatory 
implementation motivation, however, venue choice and appeal are important issues to close this model discussion with regard to some venue-by-venue and sector-by-sector features. It is inaccurate to say that market participants do not have the ability to choose where they transact. This ability depends highly on the sophistication of the investor and their access to or carrying capital sufficient to transact in different settings or at various costs. The private or dark sector, while on paper open to public participants, does not in fact resent a viable trading opportunity for the average Jo-Schmo day trader. This facet more generally motivates the assumption that only sophisticated institutional investors trade in the private sector leaving the public both information-ally and trade opportunity "stranded" in the pubic market. However, even within the private sector, venue and aggregator differences lead pools to host similar clientele.

Dark pools are often termed "toxic" when they become overrun or saturated with a certain type of trader. Venues in the dark sector often offer different types of trading opportunities, many use the term commoditized trade offerings to describe the different trade executions and types available in each venue (Banks 2010). This causes pools to become saturated with traders looking for similar types of trades depending on the trade capabilities offered in each pool. Research has also supported an increase in adverse selection within pools that offer higher probabilities of execution (Sofianos and Xiang 2011). Others have found that different variations and degrees of pool saturation and execution lead to varying biases in selection impacting prices, execution times, and transactional impacts (Mittal 2008, Naes 2006). There is strong empirical support for the notion that informed trading behavior and uninformed trading behavior tends to cluster 
itself both in time and by venue of execution, both of these dynamics function to support self selection biases within the clusters themselves. (Admati 1988, Pagano 1989, Chowdhry 1991). In short, trapping the public in the light sector while allowing the institutional investor to trade between sectors was not inaccurate, but it fails to highlight the risks associated with the institutional investor's choice of which dark venue to make his entry transaction. However, these concerns fall outside the direct relevance of instituting a reporting requirement meant to inform the light sector as to the trades taking place in the private venues, whether the venues are over saturated or not.

There is considerable additional research currently underway to both examine the behavior of dark sector participants and the general welfare concerns with the existence of dark liquidity more generally. While many believe the existence of dark liquidity to be harmful to the market as a whole, there is little empirical work in existence to suggest that the sector's effect on the market or economy as a whole is deleterious. These models and the above discussion serve only to motivate the implementation of truly real-time reporting requirements on the sector and not to suggest any additional welfare or general economic concerns with its existence outside of those relating to the unequal distribution of dark sector volume and price information.

This case comparison was not intended to kill the dark sector or to make any statements of judgment about its existence. Instead, the hope is only to inform the public as to the necessary trade specific information necessary to make the public or light market price accurate for the market as a whole. The implementation of real time reporting in the dark sector will not open the dark sector to the public for participation 
and it does not ameliorate the current difficulties associated with how information is reported through CTA. The reporting requirement only adds trade volume and price to the list of other information that reaches CTA in real-time.

There are many other nations that already have real time post trade reporting for these informational parameters. ${ }^{25}$ In both markets, even where real time post trade reporting existed the dark sector still flourished and each nation took additional steps in attempts to reduce the market share held in the dark sector (European Commission 2010, D’Antona 2012, Lionidis 2013). There are disagreements as to the exact effects that the implementation of post trade reporting can have on an already established sector of the market that had previously existed without real time reporting. The existence of a real time post trade volume and price reporting requirement does not lead to the death of a dark sector and can exist without having a deleterious effect on the growth of that sector, though it may cause the dynamics to change with regard to how pool participants execute and structure their transactions (Canadian Dark Pools Consult 2009). The goal of real time reporting is not to "kill off" the dark sector. Countries with these requirements have seen continued growth in market share going in to their dark sectors. Reporting requirements are only meant to facilitate informing the market at large to the trades that have taken place in the dark.

\footnotetext{
${ }^{25}$ Canada and Australia among others.
} 


\section{Section VII.}

\section{Dark Ends ${ }^{26}$}

The information on trade volumes and prices within venues in the dark sector is important to informing the market at large of the appropriate price for a given stock. The current regulatory framework, while mandating volume reporting, does so with a delay compared to the real-time reporting taking place in the public or light sector of the market. Participants with access to both the private and public sectors can execute trades based on knowledge learned from both sectors, while the public, without access to the information about prices and volume housed in the private sector, cannot. Instituting a real-time reporting requirement for the transactions taking place in the dark, without touching other informational parameters therein bridges the price knowledge gap and information-ally balances the information participants have about appropriate prices in the market as a whole.

Real time reporting is not in itself perfect or ideal. The current regulatory focus on high frequency trading only serves to highlight its downfalls. Many see the informational controls available in the dark sector as a cure for the worries associated with real time reporting, front running, and high frequency trading. These discussions are outside the purview of this thesis. However, whether or not more inside venue controls help to

\footnotetext{
26 "I think my eyes are getting better. Instead of a big dark blur, I see a big light blur." Han Solo, Star Wars Episode VI: Return of the Jedi (1983).
} 
ameliorate these problems the information necessary for the public to determine accurate prices must be available to all market participants, not only those who have the capital and sophistication necessary to participate in the dark sector. While the dark sector and its venues are 'open' to all participants, the costs of meaningful participation and pool membership to too costly for the average public participant. Sector participation dynamics aside, the informational access and fairness ideals supported by the reporting regulations requirements in the light sector should support the implementation of a matching volume and price reporting regime in the dark sector.

The goal of this project was two-fold, to motivate a real-time reporting requirement be implemented over trades taking place in the dark sector of the market, and to bridge both the regulatory framework and the economic foundations surrounding the informational asymmetries on the US securities market as a whole. The sectional composition of this project and the simplified structure of its brief descriptions and model reflect those two goals.

\section{END}

All errors, omission, misattributions, and misstatements herein contained are property of the author and the author alone. 


\section{Bibliography}

Admati, A. R., and Pfleiderer, P. 1988. A Theory of Intraday Patterns: Volume and Price Variability. Review of Financial Studies 1: 3-40.

Banks, Erik, "Dark Pools: The Structure and Future of Off-Exchange Trading and Liquidity (Finance and Capital Markets)" 2010

Bennett, J., Colon, J., Feng, J., and Litwin, J. 2010. Ten Questions Every Institution Should Ask Their Dark Pool Providers. Journal of Trading 5: 10-13.

Benveniste, L. M., Marcus, A. J., and Wilhelm, W. J. 1992. What's Special about the Specialist?. Journal of Financial Economics 32: 61-68.

Bloomfield, R. J., O’Hara, M., and Saar, G. 2012. Hidden Liquidity: Some New Light on Dark Trading. Working paper Cornell University.

Bond, P., Edmans, A., and Goldstein, I. 2012. The Real Effects of Financial Markets. Forthcoming, Annual Reviews of Financial Economics.

Boni, L., Brown, D. C., and Leach, J. C. 2012. Dark Pool Exclusivity Matters. Working paper.

Boulatov, A., and George, T. J. 2013. Securities Trading when Liquidity Providers are Informed. Review of Financial Studies 26: 2096-2137.

Brandes, Y., and Domowitz, I. 2010. Alternative Trading Systems in Europe: Trading Performance by European Venues Post-MiFID. Journal of Trading 5: 17-30.

Brunnermeier, M. K., and Pedersen, L. H. 2005. Predatory Trading. Journal of Finance 60: $1825-1863$.

Brunnermeier, M. K., and Pedersen, L. H. 2009. Market Liquidity and Funding Liquidity. Review of Financial Studies 22: 2201-2238.

Buti, S., Rindi, B., and Werner, I. M. 2011a. Dark Pool Trading Strategies. Working paper.

Buti, S., Rindi, B., and Werner, I. M. 2011b. Diving into Dark Pools. Working paper Fisher College of Business, Ohio State University.

Buti, S., Rindi, B., Wen, Y., and Werner, I. M. 2011. Tick Size Regulation, Intermarket Competition and Sub-Penny Trading. Working paper.

Butler, G. (2007), Liquidity aggregation; What institutional investors need to know, Journal of Trading 2:108-13. 
Butler, G. 2007. Liquidity Aggregation: What Institutional Investors Need to Know. Journal of Trading 2: 108-113.

Carlin, B. I., Lobo, M. S., and Viswanathan, S. 2007. Episodic Liquidity Crisis: Cooperative and Predatory Trading. Journal of Finance 62: 2235-2274.

Carrie, C. (2008), Illuminating the new dark influence on trading and U.S. market structure. Journal of Trading 3:40-55.

Carrie, C. 2008. Illuminating the New Dark Influence on Trading and U.S. Market Structure. Journal of Trading 3: 40-55.

CFA Institute 2009. Market Microstructure: The Impact of Fragmentation under the Markets in Financial Instruments Directive. Technical report CFA Institute.

Chakravarty, S., and Holden, C. W. 1995. An Integrated Model of Market and Limit Orders. Journal of Financial Intermediation 4: 213-241.

Chordia, T., Roll, R., and Subrahmanyam, A. 2011. Recent Trends in Trading Activity and Market Quality. Journal of Financial Economics 101: 243-263.

Chowdhry, B., and Nanda, V. 1991. Multimarket Trading and Market Liquidity. Review of Financial Studies 4: 483-511.

Comerton-Forde, C., and Putnins, T. 2012. Dark trading and price discovery. Working paper.

Conrad, J., Johnson, K. M., and Wahal, S. 2003. Institutional trading and alternative trading systems. Journal of Financial Economics 70: 99-134.

CSA/IIROC 2009. Dark Pools, Dark Orders, and Other Development in Market Structure in Canada. Consulation paper 23-404 Canadian Securities Administration and Investment Industry Regulatory Organization of Canada.

D'Antona, John Jr., Mixed Reviews for Canadian 'Trade At', Traders Magazine (June 1, 2012) http://www.tradersmagazine.com/issues/25_338/trade-at-dark-pool110076-1.html

Degryse, H., de Jong, F., and van Kervel, V. 2011. The Impact of Dark and Visible Fragmentation on Market Quality. Working paper.

Degryse, H., Van Achter, M., and Wuyts, G. 2009. Dynamic Order Submission Strategies with Competition between a Dealer Market and a Crossing Network. Journal of Financial Economics 91: 319-338. 
Domowitz, I., Finkelshteyn, I., and Yegerman, H. 2009. Cul de Sacs and Highways, An Optical Tour of Dark Pool Trading Performance. Journal of Trading 4: 16-22.

Easley, D., Keifer, N. M., and O’Hara, M. 1996. Cream-Skimming or Profit-Sharing? The Curious Role of Purchased Order Flow. Journal of Finance 51: 811-833.

European Commission 2010. Review of the Markets in Financial Instruments Directive (MiFID). Public consultation European Commission.

Feltman, Peter, CQ Roll Call 'Nasdaq Eases Routing for 'Dark Pool' Trading, 2013 WL 6491961

Feltman, Peter, CQ Roll Call "NYSE Extends Retail Access to Dark Pools Program," 2013 WL 74033624

Fin. Indus. Reg. Auth., FINRA 2010 Year In Review and Annual Financial Report 3 (2011) [URL: http://finra.org]

Fitz-Gerald, Keith, Are "Dark Pools" Destined to Be the Capital Market's Next Black Hole?, MoneyMorning.com, July 10, 2008.

Fleming, M., and Nguyen, G. 2013. Order Flow Segmentation and the Role of Dark Trading in the Price Discovery of U.S. Treasury Securities. Working paper.

Foley, S., Malinova, K., and Park, A. 2013. Dark Trading on Public Exchanges. Working paper.

Foster, D., Gervais, S., and Ramaswamy, K. 2007. The Benefits of Volume-Conditional Order-Crossing. Working paper.

Foucault, T. 1999. Order Flow Composition and Trading Costs in a Dynamic Limit Order Market. Journal of Financial Markets 2: 99-134.

Foucault, T., Kadan, O., and Kandel, E. 2005. Limit Order Book as a Market for Liquidity. Review of Financial Studies 18: 1171-1217.

Gallo, Aubrey, "XI. DARK POOL LIQUIDITY,” Review of Banking and Financial Law, 29 Rev. Banking \& Fin. L. 88 (Fall 2009).

Garfinkel, J. A., and Nimalendran, M. 2003. Market Structure and Trader Anonymity: An Analysis of Insider Trading. Journal of Financial and Quantitative Analysis 38: 591-610.

Glosten, L. R., and Milgrom, P. R. 1985. Bid, Ask and Transaction Prices in a Specialist Market with Heterogeneously Informed Traders. Journal of Financial Economics 14: $71-100$. 
Goettler, R. L., Parlour, C. A., and Rajan, U. 2005. Equilibrium in a Dynamic Limit Order Market. Journal of Finance 60: 2149-2192.

Goettler, R. L., Parlour, C. A., and Rajan, U. 2009. Informed Traders and Limit Order Markets. Journal of Financial Economics 93: 67-87.

Grammig, J., Schiereck, D., and Theissen, E. 2001. Knowing Me, Knowing You: Trader Anonymity and Informed Trading in Parallel Markets. Journal of Financial Markets 4: 358-412.

Guerrieri, V., and Shimer, R. 2012. Dynamic Adverse Selection: A Theory of Illiquidity, Fire Sales, and Flight to Quality. Working paper. University of Chicago.

Hatch, Robert, "Reforming the Murky Depths of Wall Street: Putting the Spotlight on the Security and Exchange Commissions Regulatory proposal Concerning Dark Pools of Liquidity" (July 2010).

Hendershott, T., and Jones, C. M. 2005. Island Goes Dark: Transparency, Fragmentation, and Regulation. Review of Financial Studies 18: 743-793.

Hendershott, T., and Mendelson, H. 2000. Crossing Networks and Dealer Marekts: Competition and Performance. Journal of Finance 55: 2071-2115.

Holden, C. W., and Subrahmanyam, A. 1992. Long-Lived Private Information and Imperfect Competition. Journal of Finance 47: 247-270.

International Organization of Securities Commissions 2010. Issues Raised by Dark Liquidity. Consultation report Technical Committee of the International Organization of Securities Commissions.

International Organization of Securities Commissions 2011. Principles for Dark Liquidity. Final report Technical Committee of the International Organization of Securities Commissions.

Jiang, C., McInish, T., and Upson, J. 2011. Why Fragmented Markets Have Better Market Quality: The Flight of Liquidity Order Flows to Off Exchange Venues. Working paper.

Johnson, B. (2011), Algorithmic trading \& DMA: An introduction to direct access trading strategies. London, Myeloma Press.

Johnson, B. 2010. Algorithmic Trading \& DMA: An introduction to direct access trading strategies: . 4Myeloma Press, London.

Kaniel, R., and Liu, H. 2006. So What Orders Do Informed Traders Use?. Journal of Business 79: 1867-1913. 
Kyle, A. S. 1985. Continuous Auctions and Insider Trading. Econometrica 53: 13151335 .

Langevoort, Donald C., U.S. Securities Regulation and Global Competition, 3 Va.L.\&Bus.Rev. 191-203 (2008)

Lemke, Thomas P., Lins, Gerald T., Trading and Execution: a primer - Alternative trading systems-"Dark Pools," Soft Dollars and Other Trading Activities, Chapter 1: Introduction and Overview § 1:45 (November 2012).

George Lionidis, ASIC Gets Tough on Dark Pool Activity, AUSTL. FIN. REV., Aug. 13, 2013, available at 2013 WLNR 19884138.

Macey, Jonathan, Novogrod, Caroline, Enforcing Self-Regulatory Organization's

Penalties and the Nature of Self-Regulation, 40 Hofstra L. Rev. 936 (2012).

Madhavan, A., and Cheng, M. 1997. In Search of Liquidity: Block Traders in the Upstairs and Downstairs Markets. Review of Financial Studies 10: 175-203.

Mittal, H. 2008. Are You Playing in a Toxic Dark Pool? A Guide to Preventing Information Leakage. The Journal of Trading 3: 20-33.

Næs, R., and Odegaard, B. A. 2006. Equity trading by institutional investors: To cross or not to cross?. Journal of Financial Markets 9: 79-99.

Nimalendran, M., and Ray, S. 2013. Informational Linkages Between Dark and Lit Trading Venues. Forthcoming, Journal of Financial Markets.

O'Hara, M. 2003. Presidential Address: Liquidity and Price Discovery. Journal of Finance 58: $1335-1354$.

O'Hara, M., and Ye, M. 2011. Is Market Fragmentation Harming Market Quality?. Journal of Financial Economics 100: 459-474.

Pagano, M. 1989. Trading Volume and Asset Liquidity. Quarterly Journal of Economics 104: 255-274.

Parlour, C. 1998. Price Dynamics in Limit Order Markets. Review of Financial Studies 11: 789-816.

Parlour, C. A., and Seppi, D. J. 2008. Limit Order Markets: A Survey. Chapter 3, Handbook of Financial Intermediation and Banking.

Ready, M. J. 2012. Determinants of Volume in Dark Pools. Working paper University of Wisconsin-Madison. 
Regulation ATS - Alternative Trading Systems, 17 C.F.R. §§ 242.300-.303 (2009).

Regulation NMS - Regulation of the National Market Trading System, 17 C.F.R. $\S \S$ 242.600-.621 (2009)

Regulation of Exchanges and Alternative Trading Systems, Exchange Act Release No. 34-40760, 63 Fed. Reg. 70,844, 70,847 (Dec. 22, 1998).

Rosenblatt Securities 2011. Let there be light. Market structure analysis.

Rosu, I. 2009. A Dynamic Model of the Limit Order Book. Review of Financial Studies 22: 4601-4641.

Saraiya, N., and Mittal, H. 2009. Understanding and Avoiding Adverse Selection in Dark Pools. Working paper Investment Technology Group.

SEC Open Meeting Fact Sheet, October 21, 2009, "Strengthening the Regulation of Dark Pools." [ URL: http://www.sec.gov/news/press/2009/2009-223-fs.htm]

Securities Act of 1933, 15 U.S.C $§ 77$ (2006).

Securities and Exchange Act of 1934, 15 U.S.C $§ 78$ (2006), 17 C.F.R. $§ 242.300$ (2006).

Securities Regulation Law Journal, 38 No. 1, "SEC Proposes Amendments Relating to 'Dark Pools' of Liquidity;"

Seppi, D. 1990. Equilibrium Block Trading and Asymmetric Information. Journal of Finance 45: 73-94.

Sofianos, G., and Xiang, J. 2011. Dark Pool Races, Part Two. Working paper. Goldman Sachs.

Sun, Y. 2006. The exact law of large numbers via Fubini extension and characterization of insurable risks. Journal of Economic Theory 126: 31-69.

Tabb Group 2011. Liquidity Matrix. Technical report.

Weaver, D. 2011. Off-Exchange Reporting and Market Quality in a Fragmented Market Structure. Working paper.

Ye, M. 2010. Non-execution and Market Share of Crossing Networks. Working paper University of Illinois.

Ye, M. 2011. A Glimpse into the Dark: Price Formation, Transaction Costs and Market Share of the Crossing Network. Working paper University of Illinois.

13 No. 7 Wallstreetlawyer.com: Sec. Elec. 
17 No. 4 Wallstreetlawyer.com: Sec. Elec.

187835 WL (1998) Regulation of Exchanges and Alternative Trading, S.E.C. Release No. 34-39884 (File No. S7-12-98; 17 CFR Parts 201, 240, 242 and 249; 67 S.E.C. Docket 2339) (April 17, 1998).

61 F.R. 48290-01 (1996) Order Execution Obligations, S.E.C. Release No. 34-37619A (File No. S7-30-95; 17 CFR Part 240) (September 12, 1996).

65 F.R. 51716-01 (2000) Selective Disclosure and Insider Trading, S.E.C. Release Nos. 33-7881, 34-43154, IC-24599 (File No. S7-31-99; 17 C.F.R. Parts 240, 243, and 249) (August 24, 2000).

74 F.R. $61208-01$ (2009) Regulation of Non-Pubic Trading Interests, S.E.C. Release No. 34-60997 (File No. S7-27-09; 17 C.F.R. Part 242) (November 23, 2009).

75 F.R. 3594-01 (2011) Concept Release on Equity Market Structure, S.E.C. release No. 34-61358 (File No. S7-02-10; 17 C.F.R. Part 242) (January 11, 2011).

76 F.R. 46960-01 (2011) Large Trader Reporting, S.E.C. Release No. 34-64976 (File No. S7-10-10; 17 C.F.R. Parts 240 and 249) (August 2, 2011)(Final Rule).

78 F.R. 18084-01 (2013) Regulation Systems Compliance and Integrity, S.E.C. Release No. 34-69077 (File No. S7-01-13; 7 C.F.R. Parts 242 and 249) (March 25, 2013).

8472602 WL (2011) Order Approving Proposed Rule Change, FINRA Exemptions from Equity Trade Reporting, S.E.C. Release No. 34-65695 (File No. SR-FINRA2011-051; 102 S.E.C. Docket 1478) (November 4, 2011).

5615955 WL (2013) Notice of Filing of Proposed Rule Change, FINRA To Require Alternative Trading Systems to Report Volume Information to FINRA and Use Unique Market Participant Identifiers, S.E.C. Release No. 34-70676 (File No. RFINRA-2013-042) (October 22, 2013). 
Appendix 1

Regulations and Regulatory Entities ${ }^{27}$

\section{Regulatory Documents}

Securities Act of 1933 (The Securities Act) 15 U.S.C § 77 and The Securities Exchange Act of 1934 (The Exchange Act) 15 U.S.C $\$ 77$ :

Regulatory responsibility under the Acts was delegated to the Securities and Exchange Commission; the Commission is responsible for providing and promulgating rules under the acts that protect investors and foster efficient capital formation. The 1933 Securities Act is focused on regulating the offering and classification of different securities, while the 1934 Exchange Act is focused on the exchange of securities in the primary and secondary markets. Securities exchange venues are regulated and defined within the framework of the 1934 Act while the securities and assets, which are traded on them are defined and regulated within the 1933 Act.

Regulation on Order Handling Rules (1997): Regulation OHR requires all market makers and specialists to provide their best quotations and to explicitly report the spread that each stock is being purchased and sold across (the best or lowest price at which to purchase the stock and the best or highest price at which to sell the stock). (61 F.R. 48290-01;see also; Banks 8)

Regulation of Alternative Trading Systems (1998): Regulation ATS served to greater define the regulatory application to venues within the section 6 Exchange Act definitions. (17 C.F.R. $\S \S 242.300-.303$ (2009).)

Regulation on Fair Disclosure (2000): Regulation FD required public companies, or companies whose stock is held publicly and traded on exchanges, to report certain information to the public. (65 F.R. 51716-01; see also; Banks 9)

Regulation National Market System (2005/2007/2009): Regulation NMS required that all exchanges aggregate their trading and publish (publicly) their quotations for each of the assets they carried or traded. The Regulation also required that trades be executed at the best price available at the time the trade is executed. (17 C.F.R. $\S \S$ 242.600-.621 (2009)(Regulation NMS was originally passed in 2004 and was then updated/revised in 2007 and 2009); see also; Donald C. Langevoort, U.S. Securities Regulation and Global Competition, 3 Va.L.\&Bus.Rev. 191-203 (2008).

27 "It's against my programming to impersonate a deity." - C-3PO, Star Wars: Episode VI, Return of the Jedi (1983). 


\section{Regulatory Bodies}

The Securities and Exchange Commission (SEC): Also known as The Commission. Regulatory responsibility under the 1933 and 1934 Acts was delegated to the Securities and Exchange Commission. The SEC is responsible for providing and promulgating rules under the acts that protect investors and foster efficient capital formation. The Commission is also responsible for regulating and overseeing regulation of the entities, securities, and other objects under the Acts.

The Consolidated Tape Associated (CTA): The CTA is a self-regulatory organization and has the authority from the SEC pursuant to regulation NMS to enact reporting requirements and to monitor the reporting behavior of broker-dealers and ATS's. The association is officiated by the public or light market exchanges,

Financial Industry Regulatory Authority (FINRA): FINRA is the self-regulatory organization that regulates all U.S. broker-dealers and their relationship with the investors they service. The organization and its authority were created pursuant to the 1934 Securities Exchange Act such that the organization would be selfregulatory and contain its own regulatory framework under the oversight of the SEC. FINRA is responsible for the surveillance, enforcement, and investigation of more than $80 \%$ of the U.S. equity sector.

(FINRA Website, http://www.finra.org/AboutFINRA/WhatWeDo/ ; see also; Macey, Jonathan, Novogrod, Caroline, Enforcing Self-Regulatory Organization's Penalties and the Nature of Self-Regulation, 40 Hofstra L. Rev. 936 (2012).; see also; Fin. Indus. Reg. Auth., FINRA 2010 Year In Review and Annual Financial Report 3 (2011) http://finra.org). 


\section{Appendix 2}

Terminology ${ }^{28}$

Alternative Trading Systems: Alternative trading systems are trading venues that are not regulated as exchanges. These venues match buyers and sellers and facilitate transactions, but they do not fall within the regulatory framework for public exchanges. In short, alternative trading systems are any non-exchange trading system that matches buyer and seller; this definition is very broad and covers a range of different types of venues and services.

Aggregator / Venue Aggregator: Venues aggregators exist to offer traders access to multiple venues through one hub; where the aggregator acts as the hub. An aggregator is a single hub that has access to multiple venues under its control. The aggregator does not transact or execute trades; it only provides access to the venues its houses or has access to. Because the aggregator does not execute trades, it is not subject to trade regulation, each venue is subject to regulation because each executes trades, but the aggregator is not.

Block Trading: A block trade is simply a group or large volume of shares to be transacted at once. A block can come in any size, 10 shares to 1 million shares, but it is most common to refer to block trading when discussing a large volume of shares $(1,000$ of more). Many define block trading as being specific to transactions made outside the exchange, simply because trading a block suggests that the block moves in a single transaction, and that sort of trade control does not exist through the exchanges. However, the "block" description only relates to the volume of shares grouped together for a particular transaction, large or small.

Crossing Network (CN): Defined by the Securities and Exchange Commission as an Alternative Trading System, crossing networks, “...Allow participants to enter priced orders which are then executed with matching interest at a single price, typically derived from the primary public market for each crossed security." (Securities and Exchange Commission, "Regulation of Exchanges," 1997.) Crossing networks are both the most common dark venue and the most simple venue design. The typical crossing network uses a computerized buyer-seller matching system, and allows for a variety of different informational controls surrounding the trade itself (size controls, participant controls, timing, etc).

Dark Liquidity: Also known as dark pools are also described as private trading liquidity. Dark liquidity is liquidity hat is either housed or traded in a way that does not reveal its presence, volume, price or other characteristic to the public. Many also add privacy in access to the definition because it is typically assumed that public

28 "Mmm. Lost a planet, Master Obi-Wan has. How embarrassing." - Yoda, Star Wars Episode II: Attack of the Clones (2002). 
does not have access to execute with this liquidity. The privacy or darkness of a given pool of liquidity depends on the different variety or extent to which information is shielded form the public. In this way, some pools that reveal some information to the public are termed "grey." The darkness or level of privacy in a given pool is the level of informational privacy or control that is attached to the liquidity in that pool. Additionally, many describe the darkness relating to the pool that houses the liquidity or the exchange it is traded across while others related it to the liquidity itself either existing in the public eye or not.

Dark Sector / Dark Market: The dark sector is the full culmination of the dark liquidity on the market as a whole. This sector includes all the varying degrees of darkness and includes any liquidity on the market where at least some of the informational components are private, or inaccessible to the public. Current estimates as to the market share of the dark sector in the US range form $20-40 \%$ with little support as to the accuracy of either end of that estimate. The dark sector as a whole does not have a single type of privacy, there are multiple different subsectors and subparameters that are made public and private at any time. Each pool within the sector can have a different darkness at any time and the escort as a whole is a constantly evolving landscape of black, grey, white and everything in between.

Dark Venue: A dark venue is any mechanism that executed trades consisting of dark assets or dark liquidity. The most common and most simple dark venue is the Crossing Network $(\mathrm{CN})$. These venues include any trading mechanism that allows participants to privatize information or hide informational parameters with regard to the liquidity being transacted from the public. This includes any shade or amount of informational control that takes place, grey to truly dark. These venues are often used as the tub in which a dark pool sits in the definition for a dark pool focusing on the informational controls provided by a given venue.

Informational Parameters: Informational parameters can be defined loosely as pieces of information relating to an asset, trade, or relating to other market issues. This can include the size of the trade, price of the transaction, required price, trade issuer or purchaser, trade location, trade volume, or a host of other trade related information. Parameters can both include what is reported out of trade and what information is exchanged during or before the transaction itself. Informational parameters are especially important in the dark sector where the parameters and their availability can differ from one venue to the next. In the light sector the common informational parameter is the price of a given asset.

Institutional Investor: The definitions surrounding institutional investors come in many different forms. In the context of this discussion, these are sophisticated investors who are capable of participating in both the private and public sectors of the market. This means they have the ability to use information they learn in each sector, to forecast market movements, and to strategically make trades between 
sectors and venues to best benefit themselves. These entities typically carry heavy stores of fungible capital to make trades, hedge risks, and move large sums on the market.

Liquidity: Liquidity is the ease by which the market can facilitate a trade. However, in discussing dark liquidity it is helpful to note the secondary definition hidden within the facilitation definition. Liquidity is at its base a description of the availability of shares held by parties willing to trade, and even more simply, the volume of stock that a venue or market participant has access to when trades are available. Within this definition dark liquidity facilitates trades where informational parameters can be controlled, while light liquidity facilitates public trading. The level of liquidity reveals the ease at which those trades can be undertaken, high liquidity means easy trading, low liquidity and it may be difficult to find trading opportunities.

Market Consolidation: Consolidation is essentially the opposite of fragmentation. The market condenses from many venues into several or fewer venues. This is typically a description of market behavior used to describe the more recent movement in the dark sector. While the sector started off with an explosion of many executionary venues the landscape is currently consolidating itself into a system of several venue aggregators with few independent or individual venues. Many view consolidation as the necessary result form the application of real time volume and price reporting, many view the behavior of the Canadian market following the implementation of real time reporting requirements demonstrating this dynamic.

Market Fragmentation: Generally this fragmentation can be defined as the splitting of a single market into multiple and separate sub-markets; each sub-market possessing its own liquidity and interacting forces of supply and demand. In the market as a whole, fragmentation is often discussed in relationship to liquidity moving from one sector to the other (dark/light). In the context of the dark sector alone, this is typically discussed in relationship to the early development of the sector by the emergence of many small venues dividing the sector into many small venues housing small liquidity. There are many differing views as to the results of fragmentation, increased competition as a benefit or decreased general liquidity as a set back. However, more generally, fragmentation simply describes the structure of the liquidity on the market or in a sector; spread like a sallow sea among many venues is highly fragmented, while a single deep pool has little fragmentation.

Market Share: In the context of market sectors, a market share is the percentage or volume of the market that is transacted in a sector or across a venue. The market share trading across a venue is the measure of volume in stock that gets transacted across that venue. Measuring the volume of liquidity that is exchanged in the dark sector is extremely difficult. The measurement standards among venues and 
aggregators are not uniform and market share measurement for the sector as a whole and venue by venue vary immensely and little work exists supporting a standard measure or a method to determine the accuracy of any of the volume analyses.

Price Discovery: Price discovery is the act of finding an equilibrium or market clearing price where demand for an asset and the supply of that asset clear the market or match. In the light sector price is discovered through market clearing obligations on market makers and specialists clearing book, or clearing the market of any excess shares by transacting those shares by lowering the price. The reporting of trades and market movements through real time reporting gives market participants information they need in order to interpret what an appropriate price should be and in what direction the market might be moving. Price discovery can only take place where market participants can match supply and demand through the information they receive regarding the availability of liquidity supply and the demand for current transactions.

Secondary Market: The secondary market is the market that exists after an initial public offering (IPO) has been made and investors are trading shares amongst themselves and not with the companies or issuers that issued the stock into the market during the IPO. The secondary market is the market where high frequency, dark sector, and all other proprietary trading takes place. Study related tot eh function and design of markets generally focuses on the secondary and nonIPO market unless specific investigation is taking place relating to the issuance of stock to the market.

Trade Execution: Trade execution describes the actual transaction relating to the sale or purchase of stock. In relationship to venues this is the descriptor used to differentiate between venues that transact actual purchases and sales and those that connect market participants to other venues or location where they can fulfill their transactions. Trade execution is supposed to be fast, quick and efficient. It is not true that when a market participants contacts an exchange or a broker that they are directly connecting themselves to a securities market, their transaction may go through several intermediaries before the transaction is actually executed. 